\title{
CAMURATI ENGELMANN DISEASE
}

Luciana Akita ${ }^{1, *}$, Danielly Dantas Pimentel', Viviane Alves Costa ${ }^{1}$, Juliana de Jesus Boscolo', lane Tamara Dondé1, Viviane Queiroz de Oliveira Maia', Gustavo Roberto Lourenço', Gizelle Gouvea Rezende'1, Rita de Cassia Menin¹

1.Faculdade de Medicina de São José do Rio Preto, São José do Rio Preto (SP), Brazil.

*Corresponding author: luciana.akita@gmail.com

\section{BACKGROUND}

Camurati-Engelmann disease is a rare autosomal dominant inherited bone-modeling disorder, more common in men, characterized by progressive diaphyseal cortical thickening of the long bones. Myopathic gait and pain in the affected limbs are the most frequent clinical manifestations. The diagnosis is usually difficult and delayed due to the rarity of the disease, its slow progression and the need to rule out other differential diagnosis. In this case report, we describe the diagnosing of a 67-year-old man with onset of symptoms during childhood who had a son with whom he shared the same characteristics.

\section{CASE REPORT}

A 67-year-old brown man who is a retired rural worker. He reports bilateral genu varum deformity since childhood (Fig. 1), with no neuropsychomotor development disorders. Five years ago, he started experiencing mechanical pain in the lower limbs, mainly in the knees and ankles, associated with a myopathic gait. The patient also had a son with the same deformity since childhood. Physical examination revealed mild muscular atrophy of the quadriceps femoris muscles, bilateral genu varum (Fig. 2), normal muscle strength and normal deep tendon reflexes. Laboratory tests showed normal blood count, renal function, erythrocyte sedimentation rate, phosphor-calcium metabolism and alkaline phosphatase. Long-bone radiographic findings showed cortical thickening and sclerosis (Figs. 3 and 4). Bone scintigraphy (Fig. 5) revealed increased osteoblastic activity in the proximal third of both humerus, spine, pelvis, both femurs and proximal third of right tibia. The clinical presentation, laboratory test results and radiological findings led to the diagnosis of Camurati-Engelmann disease, despite the genetic testing unavailability.
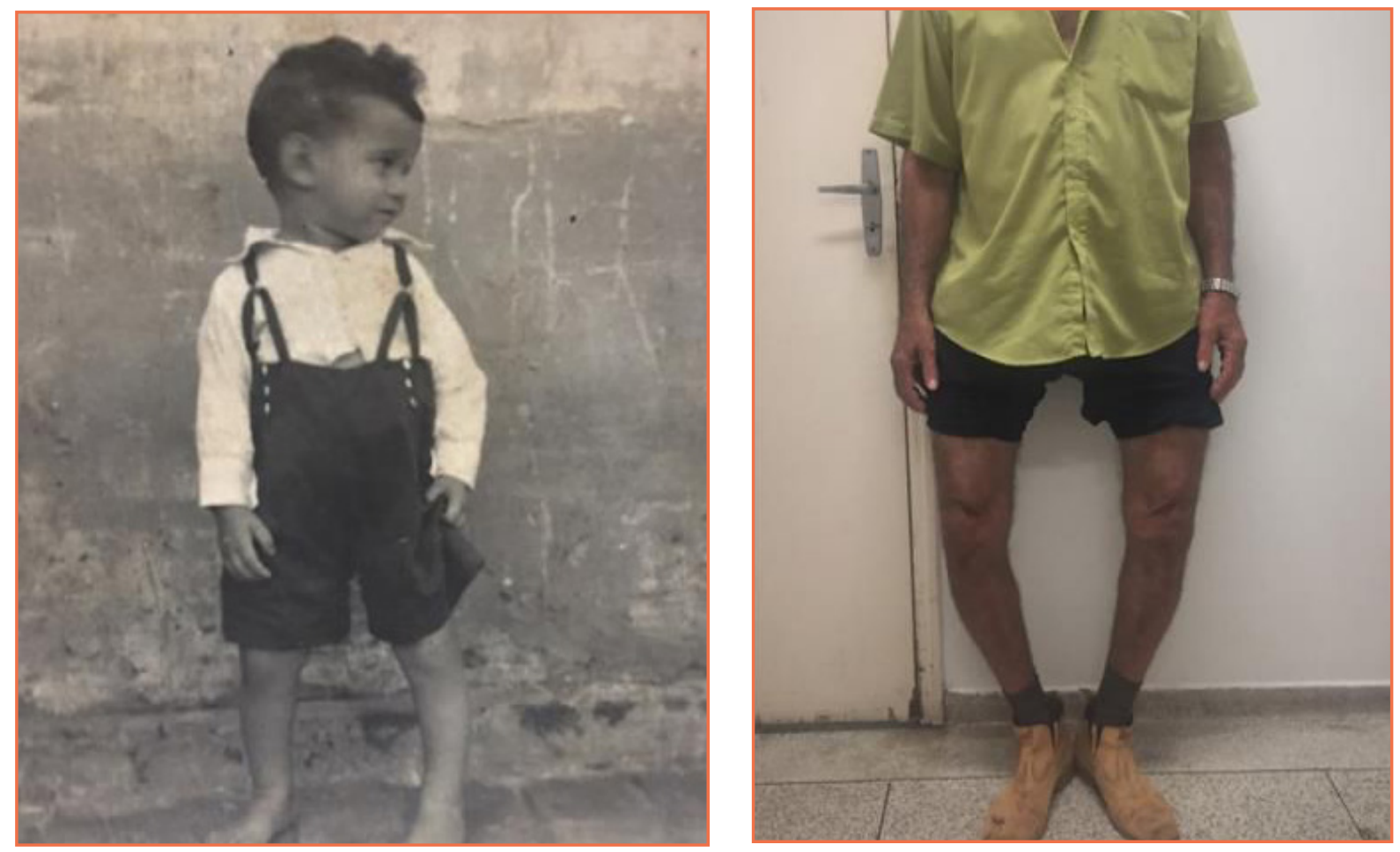

Figure 1. Childhood photo showing genu varum 


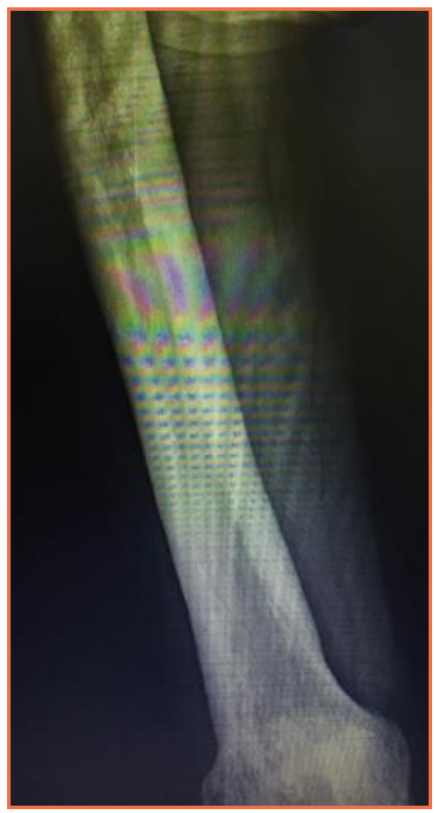

Figure 3. Right femur cortical thickening and sclerosis.

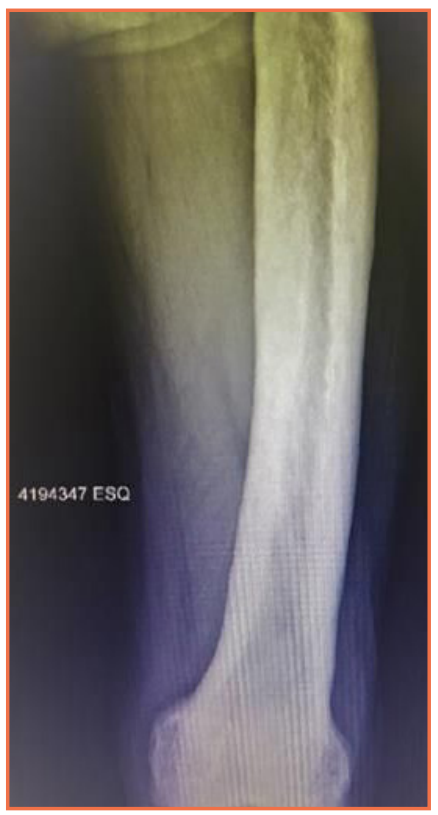

Figure 4. Left femur cortical thickening and sclerosis

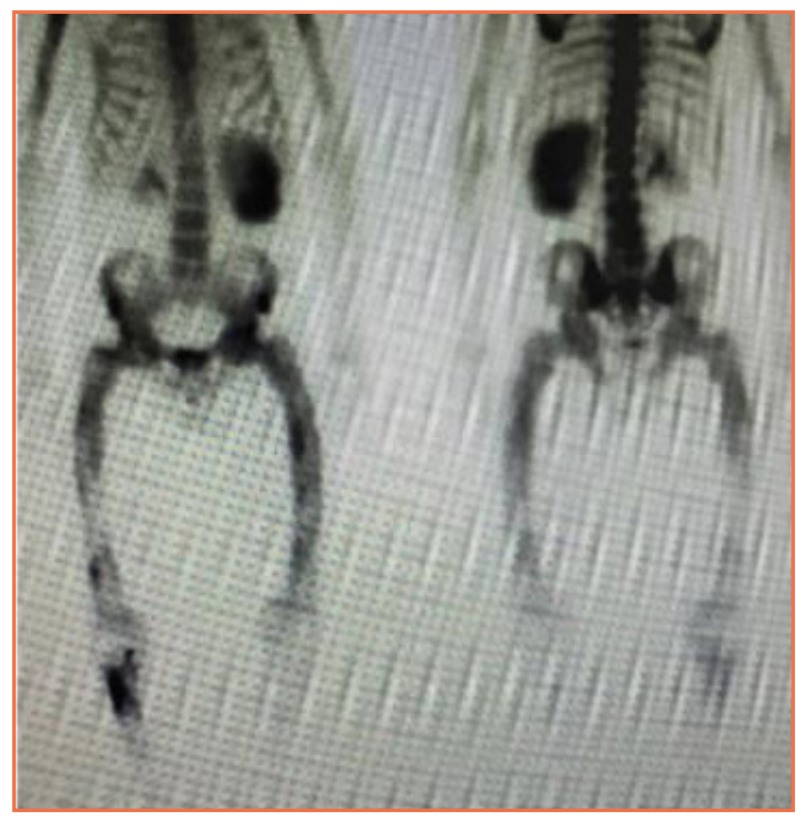

Figure 5. Bone scintigraphy showing increased osteoblastic activity in the proximal third of both humerus spine, pelvis, both femurs and proximal third of right tibia

\section{CONCLUSION}

Camurati-Engelmann disease is a rare autosomal dominant inherited bone-modeling disorder caused by a mutation in the gene encoding the transforming growth factor beta-1 (TGFb1). Myopathic gait and pain in the affected limbs are the most frequent clinical manifestations. Radiologically, there is cortical thickening and sclerosis of long bones, as well as increased osteoblastic activity in bone scintigraphy. So far, there is no treatment capable of altering the course of the disease, although glucocorticoids and nonsteroidal anti-inflammatory drugs can be used for pain management in association with physiotherapy for muscle strengthening and prevention of tendon contracture. 